\title{
Dimorfismo de Ascósporos em Glomerella cingulata f.sp. phaseoli
}

\author{
Renata A. Castro ${ }^{1}$, Maria C. Mendes-Costa ${ }^{1}$ \& Elaine A. Souza ${ }^{2}$ \\ ${ }^{1}$ Laboratório Multidisciplinar de Biologia, Centro Universitário de Lavras, CEP 37200-000, Lavras, MG, \\ e-mail: mcmcosta@unilavras.edu.br; ${ }^{2}$ Departamento de Biologia, Universidade Federal de Lavras, \\ Cx. Postal 3037, CEP 37200-000, Lavras, MG
}

(Aceito para publicação em 14/12/2006)

Autor para correspondência: Maria C. Mendes-Costa

CASTRO, R.A., MENDES-COSTA, M.C. \& SOUZA, E.A. Dimorfismo de ascósporos em Glomerella cingulata f.sp. phaseoli. Fitopatologia Brasileira 31:598-600. 2006.

\section{RESUMO}

O objetivo deste trabalho foi caracterizar linhagens de Glomerella cingulata f. sp. phaseoli quanto ao crescimento micelial, formação de peritécio e dimorfismo de ascósporos. Foram avaliadas quatro linhagens nos meios de cultura de folhas de feijoeiro e meio $\mathrm{M}_{3}$ e em condições com e sem fotoperíodo. O comprimento dos ascósporos da linhagem normal e da mutante foi determinado. Houve diferença significativa quanto ao crescimento micelial e tamanho dos ascósporos. Constatou-se, pela primeira vez, em Glomerella cingulata f. sp. phaseoli dimorfismo de ascósporos sem indução.

Palavras-chave adicionais: antracnose, crescimento micelial, morfologia.

\begin{abstract}
Dimorphism of ascospores in Glomerella cingulata $f . s p$. phaseoli

The aim of this work was to characterize Glomerella cingulata f. sp. phaseoli strains for mycelial growth, perithecia formation and ascospore dimorphism. Four strains were evaluated in common bean leaves and PDA media, with and without photoperiod. Length of the wild and mutant strains of ascospores was determined. There was asignificant difference for mycelial growth and ascospore size. This is the first time that ascospore dimorphism has been reported in Glomerella
\end{abstract} cingulata $\mathrm{f}$. sp. phaseoli.

Additional keywords: anthracnose, mycelial growth, morphology.

A antracnose, causada por Colletotrichum lindemuthianum (Sacc. \& Magn.) Briosi \& Cavara é uma das doenças mais importantes do feijoeiro comum (Phaseolus vulgaris L.). A ampla variabilidade genética apresentada por este fungo dificulta a obtenção de cultivares que apresentem resistência duradoura aos vários patótipos já identificados (Talamini et al. 2004). A fase teleomórfica, Glomerella cingulata f. sp. phaseoli Kimati (Kimati \& Galli, 1970) (Figura 1B) é facilmente obtida em laboratório por métodos convencionais (sem indução) apesar de não ser encontrada na natureza (Mendes-Costa, 1996; Camargo Jr., 2004). No entanto, a ocorrência da fase sexual é fundamental para análises genéticas e para o entendimento da estrutura populacional de fungos. Nos ascos são encontrados de 1 a 8 ascósporos, hialinos, de forma alantóide, apresentando, em média $21,7 \mu \mathrm{m}$ de comprimento e $6 \mu \mathrm{m}$ de largura (Roca et al., 2003). A dimensão e a forma dos ascósporos constituem importantes marcadores morfológicos (Panaccione et al., 1989). A ocorrência de dimorfismo conidial em Colletotrichum sublineolum P. Henn. foi utilizada para demonstração do ciclo parassexual nesta espécie (SouzaPaccola et al., 2003). Ascósporos anões de G. cingulata, isolados de Ipomea, foram obtidos por Wheeler \& Driver (1953) utilizando meio com carbono radioativo. Até o momento, não há relatos de dimorfismo de ascósporos em
G. cingulata f. sp. phaseoli. O objetivo deste trabalho foi caracterizar linhagens de Glomerella cingulata f. sp. phaseoli quanto ao crescimento micelial, formação de peritécio e dimorfismo de ascósporos.

O experimento foi realizado no Laboratório Multidisciplinar de Biologia do Centro Universitário de Lavras. As linhagens utilizadas foram provenientes da Micoteca do Laboratório de Resistência de Plantas a Doenças do Departamento de Biologia da Universidade Federal de Lavras. O experimento foi conduzido em delineamento inteiramente casualizado, no esquema fatorial $4 \times 2 \times 2$, utilizando-se quatro repetições. Quatro linhagens (L20, L42, L81 e L89) foram desenvolvidas nos meios de cultura $\mathrm{M}_{3-} 10$ grs. de sacarose, 20 grs. de Agar-agar, $2 \mathrm{~g}$. de $\mathrm{KH}_{2} \mathrm{PO}_{4}, 1 \mathrm{~g}$ de $\mathrm{MgSO}_{4} 7 \mathrm{H}_{2} \mathrm{O}, 6 \mathrm{~g}$ de neopeptona, $4 \mathrm{~mL}$ de polivitamínico e $1 \mathrm{~L}$ de $\mathrm{H}_{2} \mathrm{O}$ destilada - (Junqueira et al., 1984) e de folha de feijoeiro - 300 grs de folha de feijoeiro, 10 grs. de dextrose, 20 grs. de Agar-agar, 1L de $\mathrm{H}_{2} \mathrm{O}-\mathrm{e}$ em duas condições ambientais: com e sem fotoperíodo de 12 horas. Todas linhagens foram incubadas e mantidas em temperatura média de $24^{\circ} \mathrm{C}$. Após oito dias de crescimento as seguintes características foram avaliadas: crescimento da colônia por meio da mensuração do diâmetro em $\mathrm{cm}$ e formação de peritécio. Após 30 dias de desenvolvimento, foi verificada a formação de um setor esbranquiçado na linhagem 

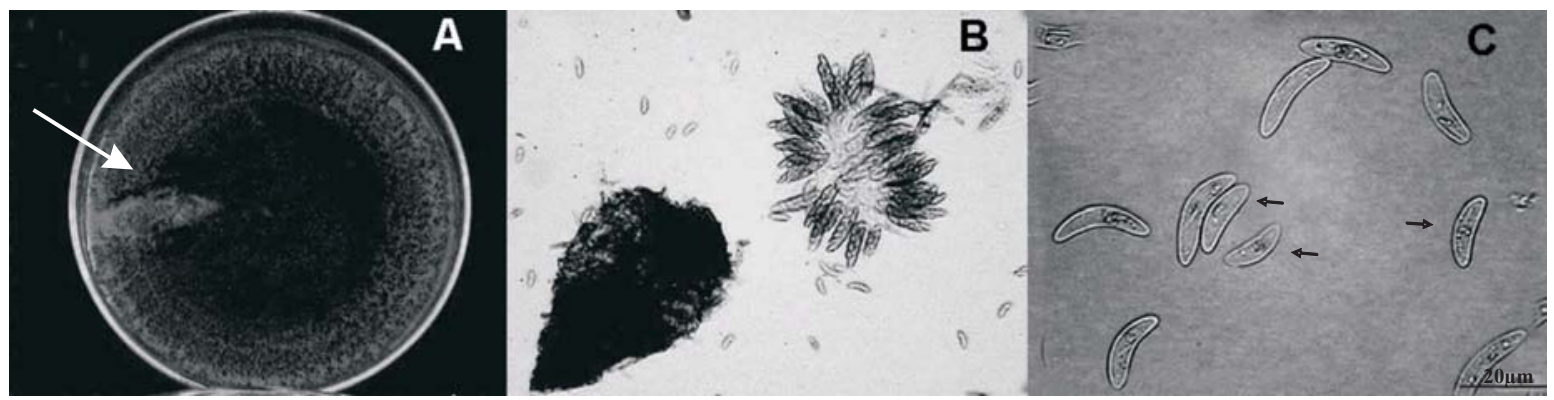

FIG. 1 - A. Placa com meio $\mathrm{M}_{3}$ mostrando setor mutante da cultura de Glomerella cingulata f. sp. Phaseoli; B. Peritécio em aumento de 10x; C. Ascósporos mutantes (seta) e normais em aumento de 40x. (barra $=20 \mu \mathrm{m}$ )

20 (Figura 1A). Neste setor foi observado aparecimento de ascósporos muito reduzidos que surgiram espontaneamente. Estes ascósporos foram caracterizados através de suas dimensões, utilizando-se a relação entre comprimento $\mathrm{x}$ largura e formato. Foram medidos, ao acaso, 30 ascósporos mutantes da linhagem L20, e 30 de tamanho normal, com auxílio do software de análise de imagens (Imagen Tool para windows versão 3.00 - UTHUSCA). A análise de variância foi realizada utilizando-se o programa SISVAR. As colônias avaliadas apresentaram coloração escura, superfície contendo pequeninos grumos (aglomeração de peritécios) e levemente aveludadas no início da germinação. Houve diferença significativa $(\mathrm{P}<0,05)$ para os efeitos de linhagens, meios e ambientes. O meio de folhas de feijoeiro proporcionou maior crescimento das colônias nas diferentes linhagens avaliadas. Como a interação linhagens $\mathrm{x}$ ambientes foi significativa (Tabela 1), procedeu-se o desdobramento para avaliar o crescimento micelial em BOD e estufa, com as linhagens diferindo entre si apenas quando avaliadas na estufa (Tabela 1). No entanto, todas as linhagens apresentaram maior crescimento quando desenvolvidas com fotoperíodo de 12 horas. Foi verificada a presença de peritécios férteis em todas as linhagens avaliadas. Como já mencionado, a linhagem 20 apresentou um setor mutante espontâneo, com formação de esporos anões. A partir da mensuração dos ascósporos da linhagem normal e do setor mutante, verificou-se que ambos possuíam formato fusiforme. No entanto, os resultados obtidos da análise de variância demonstraram diferença significativa entre a linhagem normal e a linhagem mutante quanto ao comprimento dos ascósporos. O tamanho médio dos ascósporos normais da espécie G. cingulata f.sp. phaseoli é de $21,7 \mu \mathrm{m}$ de comprimento e $5,76 \mu \mathrm{m}$ de largura (Roca et al. 2003; Souza 2005). Já os ascósporos mutantes, encontrados na linhagem 20, apresentaram em média 15,1

TABELA 1 - Resumo da análise de variância e médias do crescimento micelial (em $\mathrm{cm}$ ) de linhagens de Glomerella cingulata f. sp. phaseoli aos oito dias em dois meios de cultura e diferentes condições ambientais

\begin{tabular}{|c|c|c|c|c|}
\hline \multicolumn{2}{|l|}{ FV } & QM & Fc & $\operatorname{Pr}>$ Fe \\
\hline \multicolumn{2}{|l|}{ Ambiente } & 8,482 & 324.307 & $0,00^{*}$ \\
\hline \multicolumn{2}{|l|}{ Meio } & 0,507 & 19,409 & $0,00 *$ \\
\hline \multicolumn{2}{|c|}{ Linhagem } & 0,090 & 3,463 & $0,02 *$ \\
\hline \multicolumn{2}{|c|}{ Ambiente $*$ Linhagem } & 0,112 & 0,112 & $0,00 *$ \\
\hline \multicolumn{2}{|c|}{ Ambiente $*$ Meio } & 0,056 & 2,157 & 0,14 \\
\hline \multicolumn{2}{|c|}{ Meio * Linhagem } & 0,006 & 0,245 & 0,86 \\
\hline \multicolumn{2}{|c|}{ Ambiente $*$ Meio $*$ Linhagem } & 0,006 & 0,261 & 0,85 \\
\hline \multicolumn{2}{|c|}{ Erro } & 0,026 & & \\
\hline \multicolumn{2}{|c|}{$\mathrm{CV}(\%)=$} & 4,78 & & $* \mathrm{P}<0,05$ \\
\hline \multirow[b]{2}{*}{ Linhagens } & \multicolumn{2}{|c|}{ Meios de cultura } & \multicolumn{2}{|c|}{ Ambientes } \\
\hline & M3 & $\begin{array}{c}\text { Folhas } \\
\text { Feijoeiro }\end{array}$ & $\begin{array}{c}\text { Com fotoperíodo/ } \\
\text { BOD }\end{array}$ & $\begin{array}{c}\text { Sem fotoperíodo/ } \\
\text { Estufa }\end{array}$ \\
\hline L20 & $3,35 \mathrm{~b}$ & $3,56 \mathrm{a}$ & $3,70 \mathrm{a}$ & $3,21 \mathrm{~b}$ \\
\hline L42 & $3,20 \mathrm{~b}$ & $3,41 \mathrm{a}$ & $3,68 \mathrm{a}$ & $2,92 \mathrm{~b}$ \\
\hline L81 & $3,26 \mathrm{a}$ & $3,41 \mathrm{a}$ & $3,77 \mathrm{a}$ & $2,90 \mathrm{~b}$ \\
\hline L89 & $3,37 \mathrm{a}$ & $3,51 \mathrm{a}$ & $3,84 \mathrm{a}$ & $3,05 \mathrm{~b}$ \\
\hline
\end{tabular}

${ }^{1}$ Médias seguidas pela mesma letra na linha, não diferem significativamente pelo teste Scott-Knot (1974) ao nível de 5\%. 
$\mu \mathrm{m}$ de comprimento e $4,4 \mu \mathrm{m}$ de largura (Figura 1C). Esses resultados comprovam a ocorrência de dimorfismo de ascósporos em Glomerella cingulata f.sp. phaseoli constituindo-se do primeiro relato nesta espécie em isolados de Phaseolus vulgaris. As demais linhagens apresentaram em média as seguintes dimensões (comprimento x largura) respectivamente: $\mathrm{L} 42-22,3 \mu \mathrm{m} \times 7,2 \mu \mathrm{m}$; L81 - 23,8 $\mu \mathrm{m}$ x 6,4; L89 - 23,5 $\mu \mathrm{m}$ x 6,2 $\mu \mathrm{m}$. Na literatura há apenas o relato de Wheeler \& Driver (1953) sobre a ocorrência de ascósporos anões em $G$. cingulata, através de indução com carbono radioativo apresentando comprimento médio de 9,5 $\mu \mathrm{m}$ para os mutantes e $24,1 \mu \mathrm{m}$ para os ascósporos normais. Os dados citados, comparados com os obtidos, mostram que a linhagem mutante descoberta é intermediária entre o ascósporo normal e o mutante anão relatado por Wheeler \& Driver (1953) podendo ser utilizado como marcador morfológico em análises genéticas desta espécie.

\section{AGRADECIMENTOS}

Agradecemos ao apoio técnico prestado por Carlos Alberto Palhares e Alex Ribeiro Oliveira.

\section{REFERÊNCIAS BIBLIOGRÁFICAS}

CAMARGO JUNIOR, O.A. Identificação de recombinantes de Glomerella cingulata f. sp. phaseoli por meio de marcadores RAPD. Dissertação de Mestrado em Genética e Melhoramento de Plantas. Lavras MG. Universidade Federal de Lavras. 2004.

ISHIKAWA, F.H., SOUZA, E.A. \& DAVID, L.C. Polimorfismo cromossômico do Colletotrichum lindemuthianum agente causal da antracnose no feijoeiro. Resumos, $49^{\circ}$ Congresso Nacional de Genética, Águas de Lindóia, SP. 2003, nº 1104.
JUNQUEIRA, N.T.V., CHAVES, G.M., ZAMBOLIM, L., ROMEIRO, R.S. \& GASPAROTO, L. Isolamento, cultivo e esporulação de Microcylus ulei, agente etiológico do mal das folhas de seringueira. Ceres 31:322-331. 1984.

KIMATH, H. \& GALLI, F. Glomerella cingulata (Stonem.) Spauld. \& Schrenk. f. sp. phaseoli, fase ascogêna do agente causal da antracnose no feijoeiro. Anais da ESALQ, Piracicaba, 27:411437. 1970.

MENDES-COSTA, M.C. Genetics of Glomerella cingulata f. sp. phaseoli I. Sexual compatibility. Revista Brasileira de Genética 19(Supl.):350. 1996. (Resumo)

PANACCIONE, D.G., VAILLANCOURT, L.J. \& HANAU, R.M. Conidial dimorphism in Colletotrichum graminicola. Mycologia 81:876-883. 1989.

ROCA, M.G.M, DAVID, L.C. \& MENDES-COSTA, M.C. Cytogenetics of Colletotrichum lindemuthianum (Glomerella cingulata f. sp. phaseoli). Fitopatologia Brasileira 28:367-373. 2003.

SOUZA, B.O. Variabilidade em isolados de Colletotrichum lindemuthianum (Glomerella cingulata $\mathrm{f}$. $\mathrm{sp}$. phaseoli) por meio de marcadores morfológicos. Dissertação de Mestrado. Lavras MG. Universidade Federal de Lavras. 2005.

SOUZA-PACCOLA, E.A., FÁVARO, L.C.L., BOMFETI, C.A., MESQUITA, S.F.P. \& PACCOLA-MEIRELLES, L.D. Cultural characterization and conidial dimorphism in Colletotrichum sublineolum. Journal Phytopathology 151:383-388. 2003.

TALAMINI, V., SOUZA, E.A., POZZA, E.A., CARRIJO, F.R.F., ISHIKAWA, F.H., SILVA, K.J.D. \& OLIVEIRA, F.A. Identificação de raças patogênicas de Colletotrichum lindemuthianum a partir de isolados provenientes de regiões produtoras de feijoeiro comum. Summa Phytopathologica 30:371-375. 2004.

WHEELER, H.E. \& DRIVER, C.H. Genetics and cytology of a mutant, dwarf-spored Glomerella. American Journal of Botany 40:694-702. 1953. 